\title{
Optimization for Relay-Assisted Broadband Power Line Communication Systems with QoS Requirements Under Time-varying Channel Conditions
}

\author{
Xiaolin $\mathrm{Wu}^{1}$, Bin $\mathrm{Zhu}^{1}$, Yang Wang ${ }^{1}$ and Yue Rong ${ }^{2}$ \\ ${ }^{1}$ College of Communication Engineering, Chongqing University \\ Chongqing 400040, China \\ [e-mail: xiaolin.wu@cqu.edu.cn; zhubin@cqu.edu.cn; 1063481145@qq.com] \\ ${ }^{2}$ Department of Electrical and Computer Engineering, Curtin University \\ Perth 6102, Australia \\ [e-mail: Y.Rong@curtin.edu.au] \\ *Corresponding author: Bin Zhu
}

Received February 16, 2017; revised April 21, 2017; revised May 17, 2017; accepted May 25, 2017; published October 31, 2017

\begin{abstract}
The user experience of practical indoor power line communication (PLC) applications is greatly affected by the system quality-of-service (QoS) criteria. With a general broadcastand-multi-access (BMA) relay scheme, in this work we investigate the joint source and relay power optimization of the amplify-and-forward (AF) relay systems used under indoor broadband PLC environments. To achieve both time diversity and spatial diversity from the relayinvolved PLC channel, which is time-varying in nature, the source node has been configured to transmit an identical message twice in the first and second signalling phase, respectively. The QoS constrained power allocation problem is not convex, which makes the global optimal solution is computationally intractable. To solve this problem, an alternating optimization (AO) method has been adopted and decomposes this problem into three convex/quasi-convex sub-problems. Simulation results show the fast convergence and short delay of the proposed algorithm under realistic relay-involved PLC channels. Compared with the two-hop and broadcast-and- forward (BF) relay systems, the proposed general relay system meets the same QoS requirement with less network power assumption.
\end{abstract}

Keywords: Power line communication (PLC), relay-involved PLC channel, non-regenerative relay, Amplify-and-forward, Diversity, Power saving, Quality-of-service (QoS)

Part of this research was supported by by the Fundamental Research Funds for the Central Universities of China, with Project No. $106112016 C D J C R 161204$ and the National Natural Science Foundation of China(61571069). 


\section{Introduction}

A novel nationwide power grid based on smart-grid technology has been planned to build by The State Grid Corporation of China recently. As indoor power line communication (PLC) terminal equipment provide the most direct means to exchange information between the userpart, controller-part and provider-part in the Smart Grid, the indoor PLC technology has attracted much attention in both academia and industry [1]. Beside to electricity delivery, the indoor power cables have been used as medium, at the meantime, to support local area networks (LAN).

However, indoor power cables are not originally manufactured for high frequency (HF) signal transmission, so that indoor PLC channels demonstrate hostile characteristics for broadband communications. As summarized in [2], these hostile characteristics consist of high attenuation in HF band, frequency-selective fading in all available band, time-varying property with different time scales and presence of considerable coloured noises. These special characteristics of the point-to-point (P2P) PLC channel distinguish itself from the common wireless propagation channel. The difference between these two kind of direct transmission channels has been summarized in Table 1 [3].

Table 1. Difference between wireless and PLC channel characteristics [3].

\begin{tabular}{lll}
\hline $\begin{array}{l}\text { Channel } \\
\text { parameters }\end{array}$ & \multicolumn{2}{c}{ Wireless channel } \\
\hline Attenuation & $\begin{array}{l}\text { Highly dependent on the propagation } \\
\text { environment of interests with extensive } \\
\text { results reported in the literature }\end{array}$ & $\begin{array}{l}\text { Dependent on the characteristics of cable } \\
\text { used in the PLN }\end{array}$ \\
\hline $\begin{array}{l}\text { Frequency } \\
\text { selectivity }\end{array}$ & $\begin{array}{l}\text { Governed by reflection, diffraction, and } \\
\text { scattering }\end{array}$ & $\begin{array}{l}\text { Governed by reflections mainly due to } \\
\text { impedance discontinuities along the } \\
\text { propagation path }\end{array}$ \\
\hline Time selectivity & $\begin{array}{l}\text { Mobility of transmitter/receiver pairs or } \\
\text { motion of surrounding objects }\end{array}$ & $\begin{array}{l}\text { Impedance variations over both long and } \\
\text { short term }\end{array}$ \\
\hline Path amplitudes & $\begin{array}{l}\text { Mostly assumed Rayleigh or Ricean } \\
\text { depending on NLOS/LOS condition }\end{array}$ & $\begin{array}{l}\text { Merely resembles shadowing effect in } \\
\text { wireless channels and mostly assumed to } \\
\text { obey log-Normal PDF }\end{array}$ \\
\hline Noise & $\begin{array}{l}\text { Mostly assumed AWGN, presence of } \\
\text { impulsive noise in certain environments }\end{array}$ & $\begin{array}{l}\text { More complicated noise structure: } \\
\text { colored background noise, narrow band } \\
\text { noise and impulsive noise very effective }\end{array}$ \\
\hline
\end{tabular}

To overcome these disadvantages, many efforts have been made in order to apply advanced technologies, which were originally developed for wireless environment, into PLC channels. For example, the authors of [4] discussed a green data transmission approach to enhance the energy efficiency of PLC by jointly utilizing signal detection and resource allocation techniques; while the idea of interference alignment with delayed channel state information proposed in [5] can also be adopted into the direct transmission PLC channels. Some of matured technologies, like Windowed OFDM and Turbo Coding, have been included in the current IEEE1905 standard for indoor broadband PLC networking [6,7].

Recently, Research on introducing diversity into PLC has also been undertaken. Considering that indoor power grid cables usually consist of three conductors, namely Line, Neutral, and Protective Ground cables, every two of them can be seen as an independent port 
i.e. sub-channel, so that a low diversity order multiple-input-multiple-output (MIMO) system can be realized if all three conductors are used at the same time [8].

On the other hand, with a single pair of transmission wires, the idea of cooperative communication can be adopted into the indoor PLC environment, usually by plugging relay devices into the outlets located between the transceivers. Many system based on this idea can be found in the literature, such as two-way relay scheme for PLC [9] and cognitive radio [10] under PLC environment. Due to the broadcasting nature of the power cables, these relay devices may receive and forward the source message to the destination. The authors of [11] described a relay-assisted PLC system, based on single-frequency networking condition. The authors of [12] proposed a multi-hop transmission scheme, which combines the application of distributed space-time block code (DSTBC), for the PLC network, by assuming that every outlet on the power grid can be potentially seen as a relay node. Contrast to the P2P channel case, after relay nodes are introduced in the indoor PLC network, some notable differences will appear in the PLC channel by comparing it with the wireless relay channel. Firstly, in wireless scenarios, the source-to-relay path, source-to-destination path and the relay-to-destination path can be treated as independent to each other, and they usually share the same statistical channel model. Conversely, in PLC scenario the above three signalling paths are usually correlated, because they share the same power grid structure. Furthermore, in wireless environment, the introduction of the relay node will not influence the characteristics of the source-to-destination path given that the distance between the transceivers are much larger than the size of the relay device. However, in the PLC environment, the appearance of the relay device (with its varying impedance over different signalling phases) will affect each path gain. We refer to this situation as the relay-involved PLC channel, which has first been mentioned in [13]. A physical structure-based model for this situation has been proposed in our previous work [14], where we have shown that because the relay node changes its working mode from receiving phase to the transmitting phase, the relay-involved PLC channel is naturally time-varying, even each $\mathrm{P} 2 \mathrm{P}$ path in different phase can be assumed as time-invariant.

Generally, there are two groups of relay processing technique, namely regenerative and non-regenerative relay schemes. In the regenerative relay processing, the relay node first decodes the received signal before it recodes and forwards messages out. This technique is also referred as the decode-and-forward (DF) relaying. On the other hand, in the non-regenerative scheme, the relay node only need to amplify-and-forward (AF) its received signal. Thus, the AF relay scheme usually has shorter processing delay, lower complexity and is easier to implement. By configuring the relay node to work in an opportunistic manner, the authors of [15] examined the optimal time duration allocation between the first and the second signalling phases for both AF and DF relay schemes. Compared with the multi-hop[12] or two-hop scheme[16], the effect of the direct source-to-destination path has been considered in [15], i.e. the source node broadcasts signal to the relay and destination nodes in the first phase, and in the second phase, the relay node forwards its received signal to the destination node after certain signal processing. This configuration has also been investigated in wireless relaying scenarios, such as in [17] and [18], and we refer to it as broadcast-and-forward (BF) relay scheme. A result of BF scheme is that during the second signalling phase, the source node keeps silent. The authors of [19] took a further step and proposed a relay scheme that allows the source node to transmit in both the first and second signalling phases. In other words, the source node repeats a transmission of the same message (as in the first phase) to the destination node, while the relay node forwards its received signal, in the second phase. We refer to this as broadcast-and-multi-access (BMA) relay scheme. Under this configuration, the 
total system transmission power can be separated into the relay power and the source power, and the source power in turn should be split into two parts for transmitting the same information in two signalling phases. Compared with the above two-hop and BF relay schemes, this is a very general case as we shall see in Section 2.

Based on the relay-involved PLC channel model we proposed in [14], in this work, we adopt the general BMA relay scheme and propose a joint optimal power allocation strategy for indoor broadband PLC networks, when there are QoS requirements. Considering that the electromagnetic interference (EMI) to other nearby communication systems is a serious problem of current PLC systems, reducing total transmission power of the system can relieve this problem to some extent.

It has been pointed in [20] that for the conventional direct transmission (DT) system, the rate maximization (RM) and margin maximization (MM) problems are of duality to each other, and they admit a unique water-filling solution. However, when relay nodes has been considered in the system, this fact does not hold any more. In the literature of the PLC, relative works usually focus on maximizing a given objective function, such as signal-to-noise ratio (SNR), mutual information (MI) or system capacity, when there are some given power allocation constraints. However, the other aspect of the problem, namely minimizing the system total transmit power subjecting to the quality-of-service (QoS) constraints are not considered. Note that QoS criteria are very important for practical indoor PLC applications, such as high definition video streaming, because they greatly affect the user experience. In this work, we select the QoS criterion as the lower-bounds of the averaged sub-channel capacity(MSC) of the data-link from the source node to the destination node, which is measured in bits/s/Hz/subcarrier. As we shall see that the proposed QoS-constrained power allocation problem is not convex, to directly obtain the global optimal solution is computationally intractable. To overcome this challenge, the alternating optimization (AO) method from [21] has been adopted, so that the original problem can be decomposed into three convex/quasi-convex sub-problems.

The remainder of this work is organized as follows. Section 2 describes the system model and problem formulation. The problem formulated is a joint optimization of relay and source power allocations over two phases subjecting to minimum capacity requirement. Three decomposed convex/quasi-convex sub-problems from Section 2 have been discussed in Section 3 and 4, respectively. Based on these discussions, the overall AO algorithm has been proposed in Section 5, along with some implementation issues about this algorithm. Next, a testing relaying PLC channel has been generated to examine the AO algorithm's efficiency in Section 6, where we present some simulation examples to demonstrate the fast convergence of the proposed algorithm and superior performance of the general BMA relay scheme. Finally, Section 7 concludes this work.

\section{System model and problem formulation}

The proposed general BMA relay system is shown as block diagram in Fig. 1, which consists of three nodes, namely the source node $\mathrm{S}$, the destination node $\mathrm{D}$ and the relay node $\mathrm{R}$. We assume the relay nodes works in a time-division duplexing (TDD) mode. Let us also assume this system works under orthogonal frequency-division multiplexing (OFDM) configuration, where the system bandwidth is divided uniformly into K subcarriers. On each subcarrier, the channel fading is frequency-flat and we denote the channel response on the $k$ th $(\mathrm{k}=1,2, \cdots \mathrm{K})$ subcarrier from node $L_{1}$ to node $L_{2}$ in the nth phase as $h_{L_{1} L_{2}}^{[k],(n)}$, where $L_{1} \in\left\{\begin{array}{ll}S, & R\end{array}\right\}, L_{2} \in\left\{\begin{array}{ll}R, & D\end{array}\right\}$ and $\mathrm{n}=1,2$. 
Note that in general the relay-involved PLC channel, like the P2P PLC channel, is not frequency-flat. However, considering its relative narrow coherence bandwidth (around $60 \mathrm{KHz}$ as reported in [22]), in each sub-channel of the OFDM system, the channel response can be approximately considered flat.

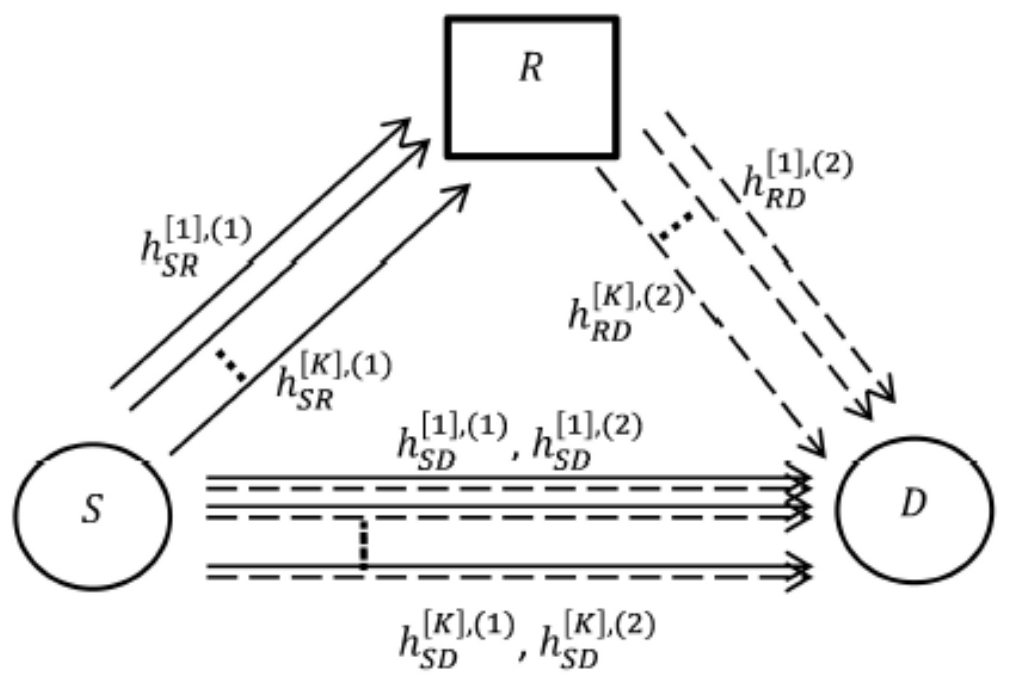

Fig. 1. A multicarrier BMA relay system, where signalling phase 1 and 2 are indicated by the so lidlines and dash-lines, respectively. S, R and D, respectively, stand for the source node, the relay node and the destination node. $\mathrm{k}=1,2, \cdots, \mathrm{K}$ here is the index of subcarriers.

In addition, the transmission power on the kth subcarrier from the source node and the relay node are written as $\mathrm{P}_{\mathrm{S}}^{[\mathrm{k}]}$ and $\mathrm{P}_{\mathrm{R}}^{[\mathrm{k}]}$, respectively. To distinguish the source power used in different signal ling phase, we use $\mathrm{P}_{\mathrm{S}, 1}^{[\mathrm{k}]}$ and $\mathrm{P}_{\mathrm{S}, 2}^{[\mathrm{k}]}$ to denote the first-phase source power and the second-phase source power, respectively, namely

$$
\mathrm{P}_{\mathrm{S}}^{[\mathrm{k}]}=\mathrm{P}_{\mathrm{S}, 1}^{[\mathrm{k}]}+\mathrm{P}_{\mathrm{S}, 2}^{[\mathrm{k}]}
$$

The total network power $\mathrm{P}_{\Sigma}$ can be written as

$$
\mathrm{P}_{\Sigma}=\sum_{\mathrm{k}=1}^{\mathrm{K}} \mathbf{P}_{\mathrm{S}}^{[\mathrm{k}]}+\sum_{\mathrm{k}=1}^{\mathrm{K}} \mathbf{P}_{\mathrm{R}}^{[\mathrm{K}]}=\sum_{\mathrm{k}=1}^{\mathrm{K}} \mathbf{P}_{\mathrm{S}, \mathbf{1}}^{[\mathrm{k}]}+\sum_{\mathrm{k}=\mathbf{1}}^{\mathrm{K}} \mathbf{P}_{\mathrm{S}, \mathbf{2}}^{[\mathrm{k}]}+\sum_{\mathrm{k}=\mathbf{1}}^{[\mathrm{k}]} \mathbf{P}_{\mathbf{R}}^{[\mathrm{k}]}
$$

Following the OFDM principle, each packet of message is encoded into $\mathrm{K}$ independent complex symbols $X^{[k]}(k=1,2, \ldots K)$ of zero mean and unit variance. To transmit a packet of message from the source node to the destination node, the BMA relay scheme works in the two signalling phases as follows.

In the first phase, the source node broadcasts information signal $X^{[k]}(k=1,2, \ldots K)$ over the kth subcarrier with the power $\mathrm{P}_{\mathrm{s}, 1}^{[\mathrm{k}]}$. Due to the broadcast nature of the indoor power grid, both the relay node and the destination node receive this signal with different channel gains and noise disturbances, respectively

$$
\begin{aligned}
& \mathrm{Y}_{\mathrm{R}, 1}^{[\mathrm{k}]}=\mathrm{h}_{\mathrm{SR}}^{[\mathrm{k}],(1)} \sqrt{\mathrm{P}_{\mathrm{S}, 1}^{[\mathrm{k}]}} \mathrm{X}^{[\mathrm{k}]}+\mathrm{N}_{\mathrm{R}, 1}^{[\mathrm{k}]} \\
& \mathrm{Y}_{\mathrm{D}, 1}^{[\mathrm{k}]}=\mathrm{h}_{\mathrm{SD}}^{[\mathrm{k}],(1)} \sqrt{\mathrm{P}_{\mathrm{S}, 1}^{[\mathrm{k}]}} \mathrm{X}^{[\mathrm{k}]}+\mathrm{N}_{\mathrm{D}, 1}^{[\mathrm{k}]}
\end{aligned}
$$

where $\mathrm{Y}_{\mathrm{R}, 1}^{[\mathrm{k}]}$ and $\mathrm{N}_{\mathrm{R}, 1}^{[\mathrm{k}]}$ denote the kth received subchannel signal and the subchannel noise, respectively, at the relay node; while $\mathrm{Y}_{\mathrm{D}, 1}^{[\mathrm{k}]}$ and $\mathrm{N}_{\mathrm{D}, 1}^{[\mathrm{k}]}$ denote the kth received subchannel signal 
and the subchannel noise, respectively, at the destination node in the first phase.

In the second phase, the relay node first amplifies its received signal $Y_{R, 1}^{[k]}$ with a proper complex gain ${ }^{[\mathrm{k}]} \exp \left(\mathrm{j}^{[\mathrm{k}]}\right)$ where $\mathrm{g}^{[\mathrm{k}]}$ is the amplitude gain and $\theta^{[\mathrm{k}]}$ is the phase shift, then it forwards the amplified signal to the destination node with power $\mathrm{P}_{\mathrm{R}}^{[\mathrm{k}]}$. At the meantime, the source node repeats the source message packet broadcasting, this time with power $\mathrm{P}_{\mathrm{D}, 2}^{[\mathrm{k}]}$. Thus at the destination node the received signal in the second phase is expressed as

$$
\mathrm{Y}_{\mathrm{D}, 2}^{[\mathrm{k}]}=\mathrm{h}_{\mathrm{RD}}^{[\mathrm{k}],(2)} \mathrm{g}^{[\mathrm{k}]} \exp \left(\mathrm{j} \theta^{[\mathrm{k}]}\right) \mathrm{Y}_{\mathrm{R}, 1}^{[\mathrm{k}]}+\mathrm{h}_{\mathrm{SD}}^{[\mathrm{k}],(2)} \sqrt{\mathrm{P}_{\mathrm{S}, 2}^{[\mathrm{k}]}} \mathrm{X}^{[\mathrm{k}]}+\mathrm{N}_{\mathrm{D}, 2}^{[\mathrm{k}]}
$$

where $\mathrm{Y}_{\mathrm{D}, 2}^{[\mathrm{k}]}$ and $\mathrm{N}_{\mathrm{D}, 2}^{[\mathrm{k}]}$ denote the $\mathrm{kth}$ received subchannel signal and the subchannel noise, respectively, at the destination node in the second phase.

According to [23], generally the noise in PLC can be classified into two board categories, namely the general background noise (GBN) and the impulsive noise. In common, the GBN often has a stable power spectrum density (PSD) over seconds, minutes and even hours. On the other hand, the impulse noise may change rapidly within microseconds and milliseconds. Considering its more fundamental property, in this paper, we only consider the impact of the GBN, so that we can reasonably assume that the noise PDF is stationary over two successive signalling phases and use $\mathrm{W}_{\mathrm{L}_{2}}^{[\mathrm{k}]}$ to denote the power of noise at node $\mathrm{L}_{2}$ in two phases. Thus we can write

$$
\begin{aligned}
g^{[\mathrm{k}]} & =\sqrt{\frac{\mathrm{P}_{\mathrm{R}}^{[\mathrm{k}]}}{\left.\left.\mathrm{P}_{\mathrm{S}, 1}^{[\mathrm{k}]}\right|_{\mathrm{SR}} ^{[\mathrm{k},(1)}\right|^{2}+\mathrm{W}_{\mathrm{R}}^{[\mathrm{k}],(2)}}} \\
\theta^{[\mathrm{k}]} & =\angle \mathrm{h}_{\mathrm{SD}}^{[\mathrm{k}],(2)}-\angle \mathrm{h}_{\mathrm{SR}}^{[\mathrm{k}],(1)}-\angle \mathrm{h}_{\mathrm{RD}}^{[\mathrm{k}],(2)}
\end{aligned}
$$

where $\angle(\cdot)$ means taking the angle of a complex number.

Actually the value of $\theta^{[\mathrm{k}]}$ in (7) is a phase adjuster. It takes the role of making the two signal components (from the direct path and the relay path, respectively) in (5) cophase to each other. Finally, the destination node combines the two copies of received signal (4) and (5) over two phases by maximum ratio combining (MRC) processing with the knowledge of channel state information (CSI). More details of this MRC processing can be found in [24].

Let us denote the normalized signalling path gain from $L_{1}$ to $L_{2}$ in the $n t h(n=1,2)$ phase as

$$
\gamma_{\mathrm{L}_{1} \mathrm{~L}_{2}}^{[\mathrm{k}],(\mathrm{n})}=\frac{\left|\mathrm{h}_{\mathrm{h}_{1} \mathrm{~L}_{2}}^{[\mathrm{kL}]}\right|^{2}}{\mathrm{w}_{\mathrm{L}_{2}}^{[\mathrm{k}]}}
$$

and denote the SNR of the kth subcarrier at the destination node (D) in the nth phase as $\operatorname{SNR}_{\mathrm{D}, 1}^{[\mathrm{k}]}$, then from (3)-(7) we have

and

$$
\mathrm{SNR}_{\mathrm{D}, 1}^{[\mathrm{k}]}=\mathrm{P}_{\mathrm{S}, 1}^{[\mathrm{k}]} \gamma_{\mathrm{SD}}^{[\mathrm{k}],(1)}
$$

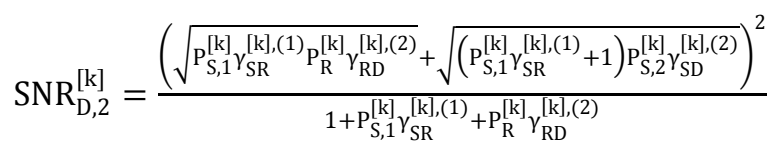

Thus, we obtain the mean sub-channel capacity (MSC), which is measured in bits/s/ Hz/ sub-carrier, of the data-link from $\mathrm{S}$ to $\mathrm{D}$ as

$$
\overline{\mathrm{C}}=\frac{1}{2 \mathrm{~K}} \sum_{\mathrm{k}=1}^{\mathrm{K}} \log _{2}\left(1+\mathrm{SNR}_{\mathrm{D}, 1}^{[\mathrm{k}]}+\mathrm{SNR}_{\mathrm{D}, 2}^{[\mathrm{k}]}\right)
$$

where the factor $1 / 2$ reflects the half-duplex constraint of the relay node.

Equation (11) presents the capacity of a general three-node/two-phase AF relay system, 
which includes the different special cases as follows.

1)If $\gamma_{\mathrm{SD}}^{[\mathrm{k}],(\mathrm{n})}=0$ where $\mathrm{n}=1,2$, then the system becomes a two-hop relay system where the direct signalling path is not available. In PLC scenario, this usually happens when the cable length between the source and the destination outlets is very long, which makes the direct source-to-destination link very weak.

2) If $P_{S, 2}^{[k]}=0$ then the system becomes a BF relay system as we mentioned in introduction.

3) Interestingly, if $\mathrm{P}_{\mathrm{R}}^{[\mathrm{k}]}=0$, which means the relay node is not active, then the system becomes a two-phase direct transmission system, where the source transmits the same information packet twice independently in two phases to achieve time diversity.

4) If $\mathrm{P}_{\mathrm{R}}^{[\mathrm{k}]}=0$ and $\mathrm{P}_{\mathrm{S}, 2}^{[\mathrm{k}]}=0$, the scheme degrades to a conventional direct transmission (DT) system ${ }^{\dagger}$.

Without losing generality, we assume $\gamma_{\mathrm{L}_{1} \mathrm{~L}_{2}}^{[\mathrm{k}](\mathrm{n})}>0$ in the following. By setting QoS criteria as the lower-bound of the system MSC, we propose the following optimization problem to explore the most efficient utilization of the system power, namely

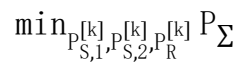

$$
\begin{aligned}
& \text { s.t. } \quad \overline{\mathrm{C}} \geq \overline{\mathrm{q}} \text {, } \\
& \mathrm{P}_{\mathrm{S}, 1}^{[\mathrm{k}]}, \mathrm{P}_{\mathrm{S}, 2}^{[\mathrm{k}]}, \mathrm{P}_{\mathrm{R}}^{[\mathrm{k}]} \geq 0, \forall \mathrm{k}
\end{aligned}
$$

where (12a) is the objective function of the total network transmission power, and $\bar{q} \geq 0$ is the required minimum link MSC to support certain applications on the indoor PLC network, e.g. HDTV inter-room sharing service.

Note the problem formulated in (12a)-(12c) has threefold tasks. Firstly, it should distribute the total system power optimally on each subcarrier; Secondly, the power of each subcarrier needs to be optimally allocated to the relay node and the source; Thirdly, for the power at the source node, it in turn needs to be split into two phases properly. The exact solution to the problem (12a)-(12c) is difficult to obtain, because the system minimum MSC constraint in (12b) is not convex. To over solve this problem, we provide a locally optimal solution by adopting the AO approach from [21]. Firstly we optimize $\mathrm{P}_{\mathrm{R}}^{[\mathrm{k}]}$ with given $\mathrm{P}_{\mathrm{S}, 1}^{[\mathrm{k}]}$ and $\mathrm{P}_{\mathrm{S}, 2}^{[\mathrm{k}]}(\mathrm{k}=1$, $2, \ldots \mathrm{K}$ ); then optimize $\mathrm{P}_{\mathrm{S}, 1}^{[\mathrm{k}]}$ with given $\mathrm{P}_{\mathrm{S}, 2}^{[\mathrm{k}]}$ and previously optimized $\mathrm{P}_{\mathrm{R}}^{[\mathrm{k}]}$; next we optimize $\mathrm{P}_{\mathrm{S}, 2}^{[\mathrm{k}]}$ with previously obtained $\mathrm{P}_{\mathrm{S}, 1}^{[\mathrm{k}]}$ and $\mathrm{P}_{\mathrm{R}}^{[\mathrm{k}]}$. We repeat this process till convergence, namely the difference between the $\mathrm{P}_{\Sigma}$ obtained in two consecutive iterations is less than a preset threshold. For any two groups of fixed power allocation parameters, the resulting sub-problem becomes convex or quasi- convex. So that we can develop the overall algorithm to solve the problem (12a)-(12c). The detailed discussion on these issues comes in the next two sections.

\section{Optimal relay power allocation with given source power allocations}

Let $\mathrm{x}_{\mathrm{k}}$ stand for $\mathrm{P}_{\mathrm{R}}^{[\mathrm{k}]}(\mathrm{k}=1,2, \ldots \mathrm{K})$. For fixed $\mathrm{P}_{\mathrm{S}, 1}^{[\mathrm{k}]}$ and $\mathrm{P}_{\mathrm{S}, 2}^{[\mathrm{k}]}$, problem (12a)-(12c) becomes

$$
\left.\begin{array}{ccc} 
& \min _{x_{k}} & \sum_{k=1}^{K} x_{k} \\
\text { s.t. } \quad 2 K \bar{q}-\sum_{k=1}^{K} \log _{2}\left(A_{k}+\frac{D_{k}+E_{k} \sqrt{x_{k}}}{B_{k}+C_{k} x_{k}}\right.
\end{array}\right) \leq 0
$$

$$
\mathrm{x}_{\mathrm{k}} \geq 0, \forall \mathrm{k}
$$

\footnotetext{
${ }^{\dagger}$ In this case, the relay's half-duplex factor $1 / 2$ does not exist.
} 
Where

$$
\begin{aligned}
\mathrm{A}_{\mathrm{k}} & =1+\mathrm{P}_{\mathrm{S}, 1}^{[\mathrm{k}]} \gamma_{\mathrm{SD}}^{[\mathrm{k}],(1)}+\mathrm{P}_{\mathrm{S}, 1}^{[\mathrm{k}]} \gamma_{\mathrm{SR}}^{[\mathrm{k}],(1)} \\
\mathrm{B}_{\mathrm{k}} & =1+\mathrm{P}_{\mathrm{S}, 1}^{\mathrm{k}]} \gamma_{\mathrm{SR}}^{[\mathrm{k}],(1)} \\
\mathrm{C}_{\mathrm{k}} & =\gamma_{\mathrm{RD}}^{[\mathrm{k}](2)} \\
\mathrm{D}_{\mathrm{k}} & =\left(1+\mathrm{P}_{\mathrm{S}, 1}^{[\mathrm{k}]} \gamma_{\mathrm{SR}}^{[\mathrm{k}],(1)}\right)\left(\mathrm{P}_{\mathrm{S}, 2}^{[\mathrm{k}]} \gamma_{\mathrm{SD}}^{[\mathrm{k}],(2)}-\mathrm{P}_{\mathrm{S}, 1}^{[\mathrm{k}]} \gamma_{\mathrm{SR}}^{[\mathrm{k}],(1)}\right) \\
\mathrm{E}_{\mathrm{k}} & =2 \sqrt{\mathrm{P}_{\mathrm{S}, 1}^{[\mathrm{k}]} \gamma_{\mathrm{SR}}^{[\mathrm{k}],(1)} \mathrm{P}_{\mathrm{S}, 2}^{[\mathrm{k}]} \gamma_{\mathrm{SD}}^{[\mathrm{k}],(2)} \gamma_{\mathrm{RD}}^{[\mathrm{k}],(2)}\left(1+\mathrm{P}_{\mathrm{S}, 1}^{[\mathrm{k}]} \gamma_{\mathrm{SR}}^{[\mathrm{k}],(1)}\right)}
\end{aligned}
$$

Let us write down the Karush-Kuhn-Tucker (KKT) conditions [25] to the problem (13a)-(13c) as, for $\forall \mathrm{k}$,

$$
\begin{gathered}
\lambda \frac{C_{k} E_{k} x_{k}+2 C_{k} D_{k} \sqrt{x_{k}}-B_{x} E_{x}}{2 \ln 2 \sqrt{x_{k}}\left(B_{k}+C_{k} x_{k}\right)\left(A_{k} B_{k}+D_{k}+A_{k} C_{k} x_{k}+E_{k} \sqrt{x_{k}}\right)}+1=0 \\
\lambda\left|2 K \bar{q}-\sum_{k=1}^{K} \log _{2}\left(A_{k}+\frac{D_{k}+E_{k} \sqrt{x_{k}}}{B_{k}+C_{k} x_{k}}\right)\right|=0 \\
\lambda \geq 0 \\
x_{k} \geq 0
\end{gathered}
$$

The problem (13a)-(13c) is not convex on $\left\{x_{k} \mid x_{k} \geq 0, k=1,2, \cdots K\right\}$, however its global optimal solution is always located on a subset of it. To illustrate this point, an example of $F\left(x_{k}\right)=\log _{2}\left(A_{k}+\frac{D_{k}+E_{k} \sqrt{x_{k}}}{B_{k}+C_{k} x_{k}}\right)$ (when $\left.K=1\right)$ is shown in Fig. 2.

Proposition 1: The problem (13a)-(13c) is convex on $\chi=\left\{x_{k} \mid 0 \leq x_{k} \leq x_{k}^{*}, x_{k}^{*}=\frac{\left(1+\frac{2}{3} \sqrt{3}\right) B_{k}}{C_{k}}, k=1,2, \cdots K\right\}$. For fixed $\lambda>0$, the left-hand-side (LHS) of (14a) is monotone to $x_{k}$ on $\chi$. And the LHS of (14b) is a piecewise monotone function of $x_{k}$ on $\chi$.

Proof: See Appendix A.

From Proposition 1, a bisection search algorithm can be employed to solve the KTT conditions (14a)-(14d) on $\chi$, which leads to the global optimal solution of the problem (13a)-(13c).

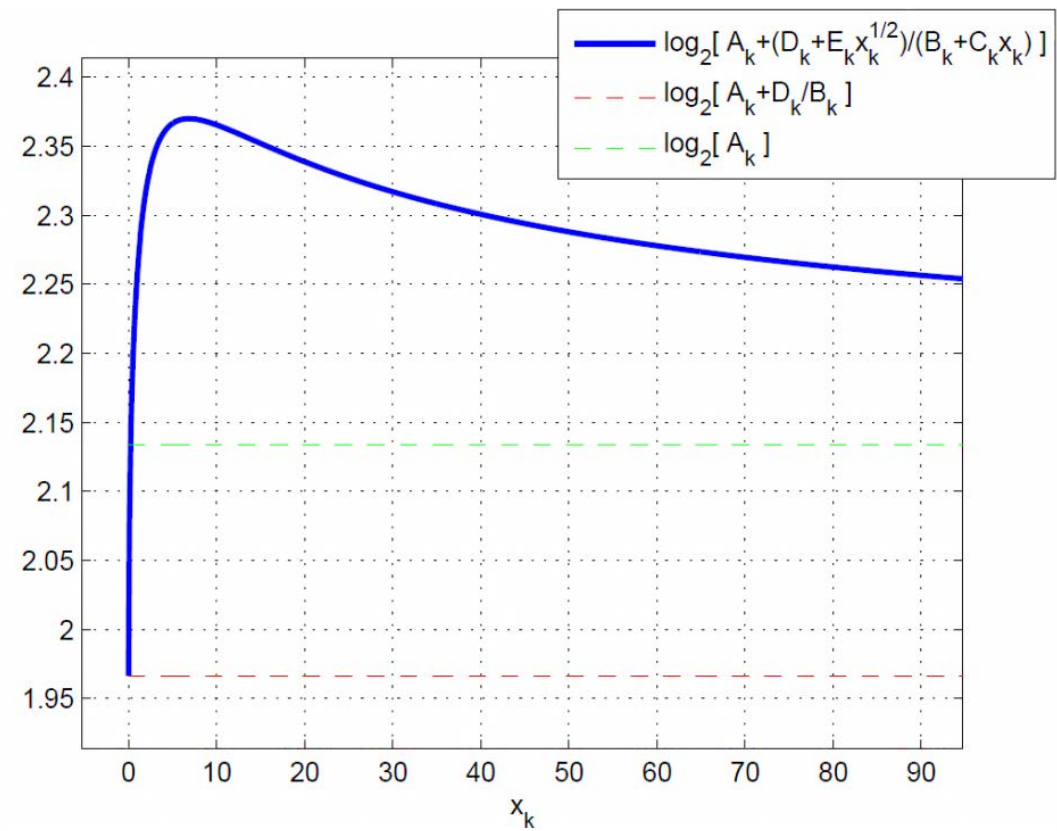

Fig. 2. Example plot of $F\left(x_{k}\right)$ versus $x_{k}$, when $K=1$. 


\section{Optimal source power allocations with given relay power allocation}

Under a given relay power allocation $\mathrm{P}_{\mathrm{R}}^{[\mathrm{k}]}$, the problem (12a)-(12c) is still a non-convex problem. Again, we apply the approach of AO and decompose this problem into two subproblems as shown in the following two subsections.

\subsection{Optimal first-phase source power allocation with given second-phase power and relay power allocations}

Let $\mathrm{y}_{\mathrm{k}}$ stand for $\mathrm{P}_{\mathrm{S}, 1}^{[\mathrm{k}]}(\mathrm{k}=1,2, \ldots \mathrm{K})$, then for given $\mathrm{P}_{\mathrm{S}, 2}^{[\mathrm{k}]}$ and $\mathrm{P}_{\mathrm{R}}^{[\mathrm{k}]}$, we now consider the optimization of the source power allocation in the first phase by solving the problem of

$$
\begin{gathered}
\min _{y_{k}} \quad \sum_{k=1}^{K} y_{k} \\
\text { s.t. } 2 K \bar{q}-\sum_{k=1}^{K} \log _{2}\left(F+G_{k} y_{k}+\frac{H_{k}+R_{k} \sqrt{y_{k}\left(1+L_{k} y_{k}\right)}}{L_{k} y_{k}+M_{k}}\right) \leq 0 \\
y_{k} \geq 0, \forall k
\end{gathered}
$$

Where

$$
\begin{aligned}
\mathrm{F}_{\mathrm{k}} & =1+\mathrm{P}_{\mathrm{R}}^{[\mathrm{k}]} \gamma_{\mathrm{RD}}^{[\mathrm{k}],(2)}+\mathrm{P}_{\mathrm{S}, 2}^{[\mathrm{k}]} \gamma_{\mathrm{SD}}^{[\mathrm{k}],(2)} \\
\mathrm{G}_{\mathrm{k}} & =\gamma_{\mathrm{SD}}^{[\mathrm{k}],(1)} \\
\mathrm{H}_{\mathrm{k}} & =-\mathrm{P}_{\mathrm{R}}^{[\mathrm{k}]} \gamma_{\mathrm{RD}}^{[\mathrm{k}],(2)}\left(1+\mathrm{P}_{\mathrm{R}}^{[\mathrm{k}]} \gamma_{\mathrm{RD}}^{[\mathrm{k}],(2)}+\mathrm{P}_{\mathrm{S}, 2}^{[\mathrm{k}]} \gamma_{\mathrm{SD}}^{[\mathrm{k}],(2)}\right) \\
\mathrm{L}_{\mathrm{k}} & =\gamma_{\mathrm{SR}}^{[\mathrm{k}],(1)} \\
\mathrm{M}_{\mathrm{k}} & =1+\mathrm{P}_{\mathrm{R}}^{[\mathrm{k}]} \gamma_{\mathrm{RD}}^{[\mathrm{k}],(2)} \\
\mathrm{R}_{\mathrm{k}} & =2 \sqrt{\gamma_{\mathrm{SR}}^{[\mathrm{k}],(1)} \mathrm{P}_{\mathrm{S}, 2}^{[\mathrm{k}]} \gamma_{\mathrm{SD}}^{[\mathrm{k}],(2)} \mathrm{P}_{\mathrm{R}}^{[\mathrm{k}]} \gamma_{\mathrm{RD}}^{[\mathrm{k}],(2)}}
\end{aligned}
$$

Let us write down the KKT conditions to the problem (15a)-(15c) as, for $\forall \mathrm{k}$,

$$
\begin{gathered}
\ln 2\left(F+G y+\frac{H+R \sqrt{L y^{2}+y}}{M+L y}\right)=\mu\left[G-\frac{L\left(H+R \sqrt{L y^{2}+y}\right)}{(M+L y)^{2}}+\frac{R(2 L y+1)}{(2 L y+2 M) \sqrt{L y^{2}+y}}\right] \\
\mu\left|2 K \bar{q}-\sum_{k=1}^{K} \log _{2}\left(F+G_{k} y_{k}+\frac{H_{k}+R_{k} \sqrt{y_{k}\left(1+L_{k} y_{k}\right)}}{L_{k} y_{k}+M_{k}}\right)\right|=0 \\
\mu \geq 0 \\
y_{k} \geq 0
\end{gathered}
$$

Proposition 2: The problem (15a)-(15c) is convex on $\left\{y_{k} \mid y_{k} \geq 0, k=1,2, \cdots K\right\}$. And for fixed $\mu>0$, both the LHS of (16a) and (16b) are monotone functions of $y_{k}$.

Proof: See Appendix B.

Based on Proposition 2, the solution to the problem (15a)-(15c) can be obtained by using a bisection search algorithm.

\subsection{Optimal second-phase source power allocation with given first-phase power and relay power allocations}

Similarly, based on the optimized $\mathrm{P}_{\mathrm{S}, 1}^{[\mathrm{k}]}$ and $\mathrm{P}_{\mathrm{R}}^{[\mathrm{k}]}$ from above,we now denote $\mathrm{P}_{\mathrm{S}, 2}^{[\mathrm{k}]}$ as $\mathrm{z}_{\mathrm{k}}$ and consider the optimization of the source power allocation in the second phase by solving the problem of

$$
\begin{array}{ll} 
& \min _{\mathrm{z}_{\mathrm{k}}} \sum_{\mathrm{k}=1}^{\mathrm{K}} \mathrm{z}_{\mathrm{k}} \\
\text { s.t. } & 2 \mathrm{~K} \overline{\mathrm{q}}-\sum_{\mathrm{k}=1}^{\mathrm{K}} \log _{2}\left(\mathrm{~S}_{\mathrm{k}}+\mathrm{T}_{\mathrm{k}} \mathrm{z}_{\mathrm{k}}+\mathrm{U}_{\mathrm{k}} \sqrt{\mathrm{z}_{\mathrm{k}}}\right) \leq 0 \\
& \mathrm{z}_{\mathrm{k}} \geq 0, \forall \mathrm{k}
\end{array}
$$


where

$$
\begin{aligned}
& \mathrm{S}_{\mathrm{k}}=1+\mathrm{P}_{\mathrm{S}, 1}^{[\mathrm{k}]} \gamma_{\mathrm{SD}}^{[\mathrm{k}],(1)}+\frac{\mathrm{P}_{\mathrm{S}, 1}^{[\mathrm{k}]} \gamma_{\mathrm{SR}}^{[\mathrm{k}],(1)} \mathrm{P}_{\mathrm{R}}^{[\mathrm{k}]} \gamma_{\mathrm{RD}}^{[\mathrm{k}],(2)}}{1+\mathrm{P}_{\mathrm{S}, 1}^{[\mathrm{k}]} \gamma_{\mathrm{SR}}^{[\mathrm{k}],(1)}+\mathrm{P}_{\mathrm{R}}^{[\mathrm{k}]} \gamma_{\mathrm{RD}}^{[\mathrm{k}],(1)}} \\
& \mathrm{T}_{\mathrm{k}}= \frac{\left(\mathrm{P}_{\mathrm{S}, 1}^{[\mathrm{k}]} \gamma_{\mathrm{SR}}^{[\mathrm{k}],(1)}+1\right) \gamma_{\mathrm{SD}}^{[\mathrm{k}],(2)}}{1+\mathrm{P}_{\mathrm{S}, 1}^{[\mathrm{k}]} \gamma_{\mathrm{SR}}^{[\mathrm{k}],(2)}+\mathrm{P}_{\mathrm{R}}^{[\mathrm{k}]} \gamma_{\mathrm{RD}}^{[\mathrm{k}],(2)}} \\
& \mathrm{U}_{\mathrm{k}}=\frac{2 \sqrt{\mathrm{P}_{\mathrm{S}, 1}^{[\mathrm{k}]} \gamma_{\mathrm{SR}}^{[\mathrm{k}],(1)} \gamma_{\mathrm{SD}}^{[\mathrm{k}],(2)} \mathrm{P}_{\mathrm{R}}^{[\mathrm{k}]} \gamma_{\mathrm{RD}}^{[\mathrm{k}],(2)}\left(1+\mathrm{P}_{\mathrm{S}, 1}^{[\mathrm{k}]} \gamma_{\mathrm{SR}}^{[\mathrm{k}],(1)}\right)}}{1+\mathrm{P}_{\mathrm{S}, 1}^{[\mathrm{k}]} \gamma_{\mathrm{SR}}^{[\mathrm{k}],(1)}+\mathrm{P}_{\mathrm{R}}^{[\mathrm{k}]} \gamma_{\mathrm{RD}}^{[\mathrm{k}],(2)}}
\end{aligned}
$$

The KKT conditions to the problem (17a)-(17c) are, for $\forall \mathrm{k}$

$$
\begin{aligned}
& 1-\delta \frac{\mathrm{T}_{\mathrm{k}}+\frac{\mathrm{U}_{\mathrm{k}}}{2 \sqrt{z_{\mathrm{k}}}}}{\ln 2\left(\mathrm{~S}_{\mathrm{k}}+\mathrm{T}_{\mathrm{k}} \mathrm{z}_{\mathrm{k}}+\mathrm{U}_{\mathrm{k}} \sqrt{\mathrm{z}_{\mathrm{k}}}\right)}=0 \\
& \delta\left[2 \mathrm{~K} \overline{\mathrm{q}}-\sum_{\mathrm{k}=1}^{\mathrm{K}} \log _{2}\left(\mathrm{~S}_{\mathrm{k}}+\mathrm{T}_{\mathrm{k}} \mathrm{z}_{\mathrm{k}}+\mathrm{U}_{\mathrm{k}} \sqrt{\mathrm{Z}_{\mathrm{k}}}\right)\right]=0 \\
& \delta \geq 0 \\
& \mathrm{z}_{\mathrm{k}} \geq 0
\end{aligned}
$$

Proposition 3: The problem (17a)-(17c) is convex on $\left\{z_{k} \mid z_{k} \geq 0, k=1,2, \cdots K\right\}$. And For fixed $\delta>0$, the LHS of (18a) and (18b) are monotonically changing with $\mathrm{z}_{\mathrm{k}}$.

Proof: See Appendix C.

Again, the solution to the problem (17a)-(17c) can be obtained by using a standard bisection algorithm.

\section{Proposed iterative algorithm}

From the discussion in the last two sections, the proposed $\mathrm{AO}$ algorithm for solving the problem (12a)-(12c) is summarized in Table 2.

Table 2. AO algorithm to solve problem (12a)-(12c)

1) Initialize $\mathrm{P}_{\mathrm{S}, 1}^{[\mathrm{k}]}, \mathrm{P}_{\mathrm{S}, 2}^{[\mathrm{k}]}$ to make (12b) and (12c) satisfied.

2) With preselected (newly obtained) $P_{S, 1}^{[k]}$ and $P_{S, 2}^{[k]}$, use bi-section algorithm to solve subproblem (14a)-(14d) to find a new set of $P_{R}^{[k]}$.

3) With preselected (newly obtained) $P_{S, 2}^{[k]}$ and $P_{R}^{[k]}$, use bi-section algorithm to solve subproblem (16a)-(16d) to find a new set of $\mathrm{P}_{\mathrm{S}, 1}^{[\mathrm{k}]}$.

4) With newly obtained $P_{R}^{[k]}$ and $P_{S, 1}^{[k]}$, use bi-section algorithm to solve (18a)-(18d) to find a new set of $\mathrm{P}_{\mathrm{S}, 2}^{[\mathrm{k}]}$.

5) With the obtained power allocation values from 2)-4), calculate the total power value (12a).

6) Go to step 2), unless the difference of the value of (12a) in two successive iterations is less than a preset threshold $\sigma$.

7) Find a stationary point of the objective function (12a).

It should be noticed that the above AO method cannot guarantee to converge to the global optimal solution in general. However, since we have obtained the global optimum for each subproblem, the proposed AO algorithm converges to a stationary point of the objective function (12a). The proof to this conclusion has been given in Appendix $\mathbf{D}$ and verified by simulation examples in the next section. 


\subsection{Complexity analysis}

As shown in Table 1, the second step is used to solve the first sub-problem (13a)-(13c). For fixed $\lambda$ and $x_{k}$, there are 19 real number multiplications needed to calculate the LHS of (14a). Thus, the complexity order to solve the sub-problem (13a)-(13c) is to be $O\left(19 \mathrm{Kc}_{\chi} \mathrm{c}_{\lambda}\right)$, where $c_{\chi}$ means the number of bi-section searches to obtain $x_{k}$, and $c_{\lambda}$ indicates the number of iterations to obtain $\lambda$.

Similarly, the third and fourth steps in Table 1 require a complex order of $O\left(21 \mathrm{Kc}_{\mathrm{y}} \mathrm{c}_{\mu}\right)$ and $O\left(9 \mathrm{Kc}_{\mathrm{z}} \mathrm{c}_{\delta}\right)$, respectively, where $\mathrm{c}_{\mathrm{y}}, \mathrm{c}_{\mu}, \mathrm{c}_{\mathrm{z}}$, and $\mathrm{c}_{\delta}$ are the number of iterations required to obtain $\mathrm{y}_{\mathrm{k}}, \mu, \mathrm{z}_{\mathrm{k}}$, and $\delta$, respectively.

Therefore, the per-iteration computational complexity order of the proposed $\mathrm{AO}$ algorithm is $\left(K\left(19 c_{x} c_{\lambda}+21 c_{y} c_{\mu}+9 c_{z} c_{\delta}\right)\right)$, which increases linearly with the number of subcarriers. The number of iterations of the AO algorithm till convergence depends on the stop criterion. It is shown in Section 6 that about eight iterations are required to achieve $\sigma=10^{-5}$.

\subsection{Implementation issue}

In practice, the CSI of $\mathrm{h}_{\mathrm{SR}}^{[\mathrm{k}],(1)}$ and $\mathrm{h}_{\mathrm{SD}}^{[\mathrm{k}],(1)}$ can be obtained at the relay node and the destination node, respectively, through standard channel training method in the first signalling phase.

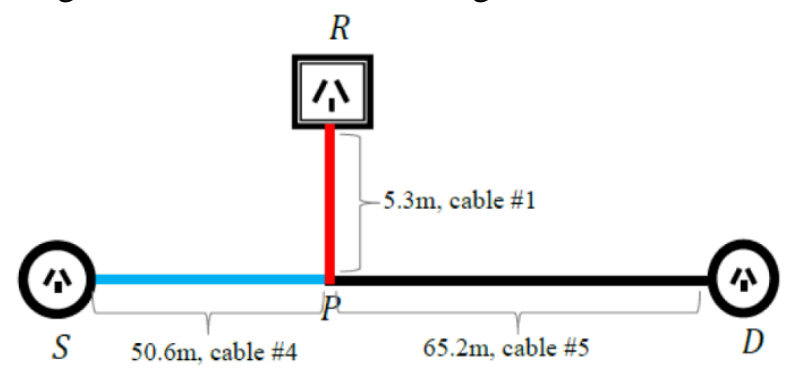

Fig. 3. Topology of the testing channel.

Similarly, in the second phase, the destination node can obtain the CSI of $h_{R D}^{[k],(2)}$ and $h_{S D}^{[k],(2)}$ with some proper channel identification technologies. Then the relay node need to forward the CSI of $h_{S R}^{[k],(1)}$ to the destination node, where the power allocation for each node can be calculated (through the proposed AO algorithm) and the results are sent to each terminal.

\section{Numerical examples}

In this section, based on a simple testing relay-involved PLC channel (which is generated by adopting our relay-involved PLC channel model ${ }^{\dagger}$ ), simulation results are presented. The testing channel's topology is shown in Fig. 3, where different segments of the network are implemented with different types of cables. The parameters of the cables can be found in [22]. Moreover, we referred to the Home Plug AV protocol [26] to set the physical (PHY) layer specification for some simulation parameters. Details about our simulation configurations are as follows.

\footnotetext{
${ }^{\dagger}$ More information about how to set parameters to generate realistic relay-involved PLC channel can be found in [8].
} 
1) For simplicity, we assume the noise on different nodes of the network are independent and identically distributed (i.i.d.). They share a common PSD as given in Fig. 4, where $\mathrm{k}=1$, $2, \ldots 1155$ means the subcarrier index.

2) Let us set the source node's inner impedance as $Z_{s}=50 \Omega$ and the receiving impedance of the destination node as $Z_{1}=150 \Omega$. For the relay node, when it works in the transmitting (Tx) mode, it has an inner impedance $\mathrm{Z}_{\mathrm{s}} \mathrm{R}=50 \Omega$, while in the receiving (Rx) mode, it has a loading impedance $\mathrm{Z}_{1} \mathrm{R}=150 \Omega$.

3) A preexisting load $Z_{b}$ has been deployed on the outlet where the relay device is plugged in. The frequency response of $Z_{b}$ is given in Fig. 5 .

4) With our relay-involved PLC channel generation approach [14], each signalling path in Fig. 3 can be treated as an equivalent P2P channel, and the latter one's channel gain can be easily realized by the configuring cable's parameters properly. A group of these correlated path gains $\left(\mathrm{h}_{\mathrm{SD}}^{[\mathrm{k}],(1)}, \mathrm{h}_{\mathrm{SR}}^{[\mathrm{k}],(1)}, \mathrm{h}_{\mathrm{RD}}^{[\mathrm{k}],(2)}\right.$ and $\left.\mathrm{h}_{\mathrm{SD}}^{[\mathrm{k}],(2)}\right)$ have be given in Fig. 6 indiscrete from. Note in Fig. 6 the conventional P2P channel gain $\tilde{\mathrm{h}}_{\mathrm{SD}}^{[\mathrm{k}]}$ is also given, which corresponds to the situation where the relay device is unplugged from the grid. We can see that the appearance of relay node changes the gain of the direct source-to-destination path. In this situation, the source-to-destination path cannot be simply treated as the concatenation of the source-to-relay path and the relay- to-destination path (as in the wireless relay case), i.e.

$$
\tilde{\mathrm{h}}_{\mathrm{SD}}^{[\mathrm{k}]} \neq \mathrm{h}_{\mathrm{SR}}^{[\mathrm{k}],(1)} \mathrm{h}_{\mathrm{RD}}^{[\mathrm{k}],(2)}
$$

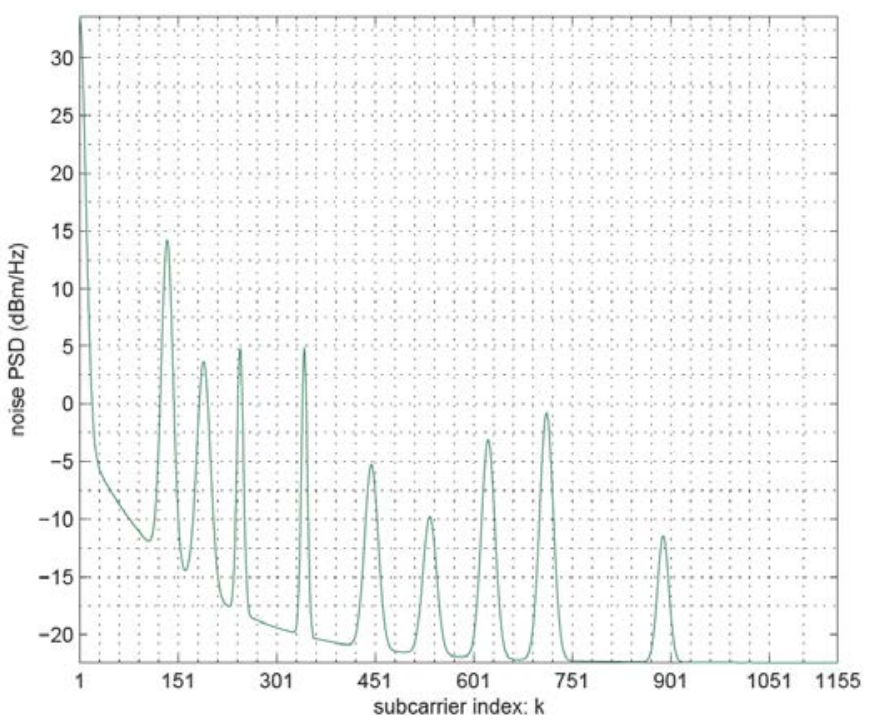

Fig. 4. Testing noise PSD at the testing PLC network. 


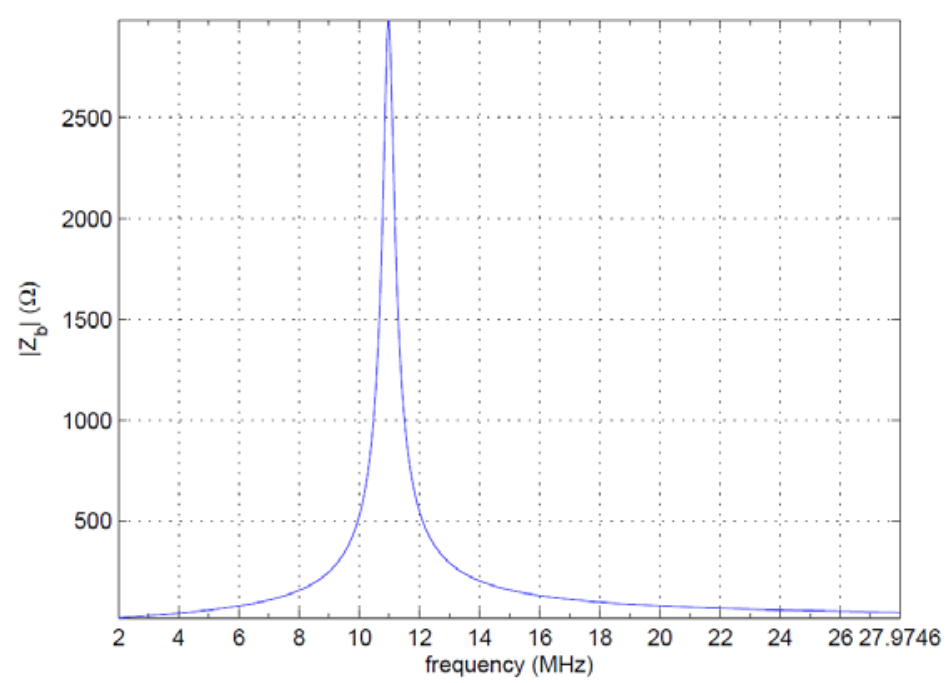

Fig. 5. Frequency response of preexisting load $\mathrm{Z}_{\mathrm{b}}$.

5) By using (8), we can calculate the normalized path gains $\left(\gamma_{S D}^{[\mathrm{k}],(1)}, \gamma_{\mathrm{SR}}^{[\mathrm{k}],(1)}, \gamma_{\mathrm{RD}}^{[\mathrm{k}],(2)}\right.$ and $\left.\gamma_{\mathrm{SD}}^{[\mathrm{k}],(2)}\right)$ on each subcarrier.They are shown in Fig. 7.

In addition, for the proposed AO algorithm, the convergence condition as the difference between the total power obtained in two successive iterations is set to be $10^{-5}$. Table 3 summarized the parameters for the simulation.

Table 3. System parameters used for simulation

\begin{tabular}{lc}
\hline \multicolumn{1}{c}{ Frequency band } & from 2MHz to 28MHz \\
\hline Total subcarriers number & $\mathrm{K}=1155$ \\
General background noise & As shown in Fig. 4 \\
Signalling path gains & As shown in Fig. 6 \\
Normalized path gains & As shown in Fig. 7 \\
\hline
\end{tabular}

To demonstrate the convergence speed of the AO algorithm, we first set the minimal MSC requirement $\bar{q}$ in (12b) to five different values, i.e. from 1.0 to $3.0 \mathrm{bits} / \mathrm{s} / \mathrm{Hz} / \mathrm{subcarrier}$.The resulted total transmission power $\mathrm{P}_{\Sigma}$ w.r.t the numberof iterations is shown in Fig. 8. We can see that the proposed AO algorithm converges typically within eight iterations. Actually, after six iterations the decreasing of the total power is very small. Thus, a good performance asks only a few iterations to achieve. Fig. 8 also indicates that the AO algorithm has a short processing delay, which is very important for practical PLC relay systems. 


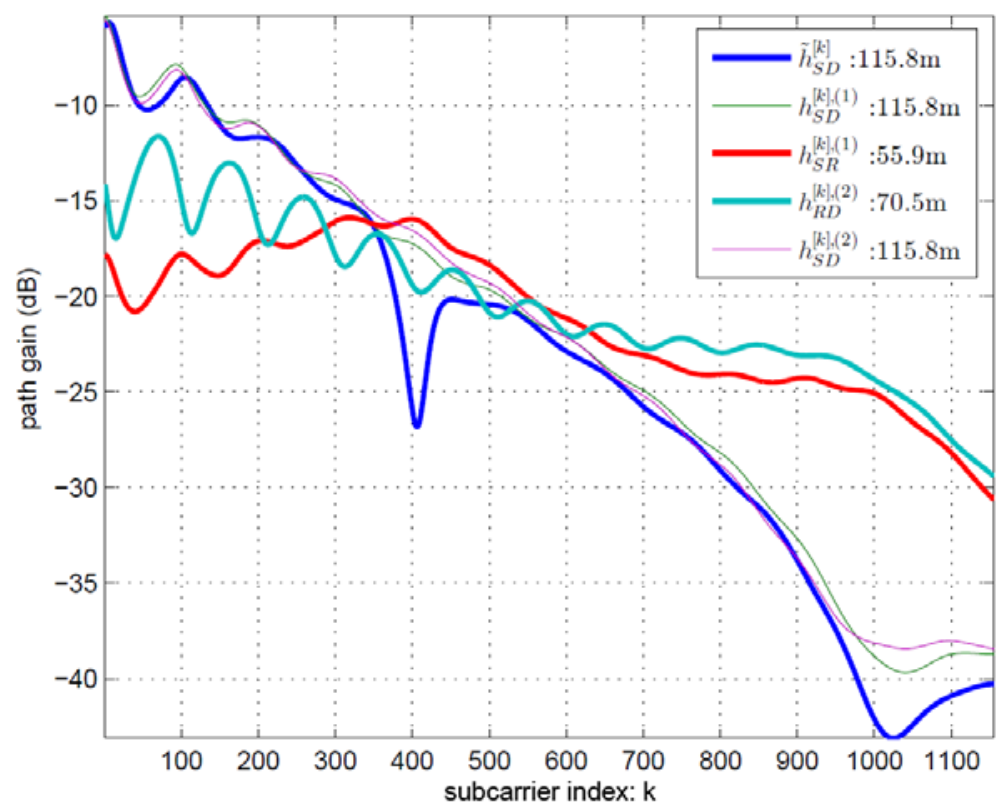

Fig. 6. Different path gains existing in the testing relay-involved channel where the conventional P2P channel gain has also been given for comparison.

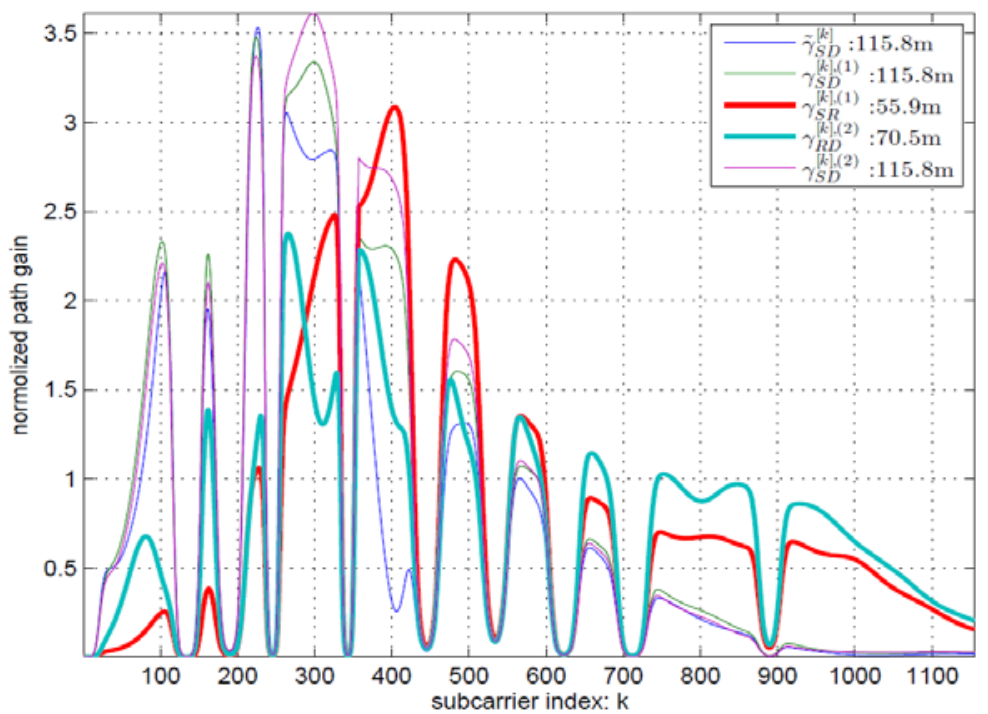

Fig. 7. Different normalized path gains existing in the testing relay-involved channel where the conventional P2P situation has also been given for comparison.

Next, we compare the proposed general BMA relay scheme (which is optimized by the AO power allocation algorithm) with the two-hop relay system and the BF relay system in the same testing channel condition. We can see from Fig. 9 that the BF scheme has a better 


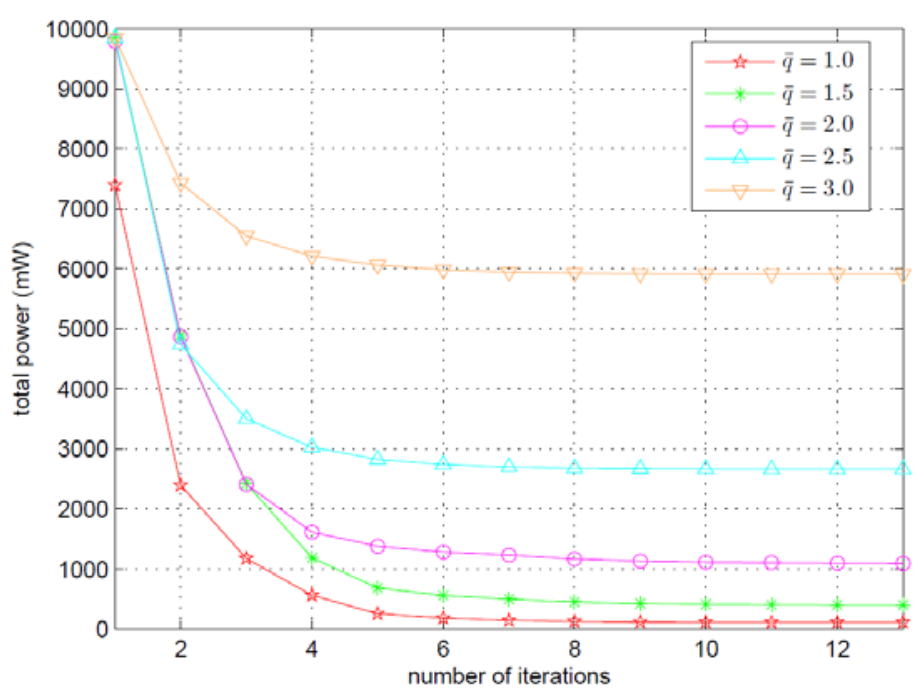

Fig. 8. Total power versus number of iterations.

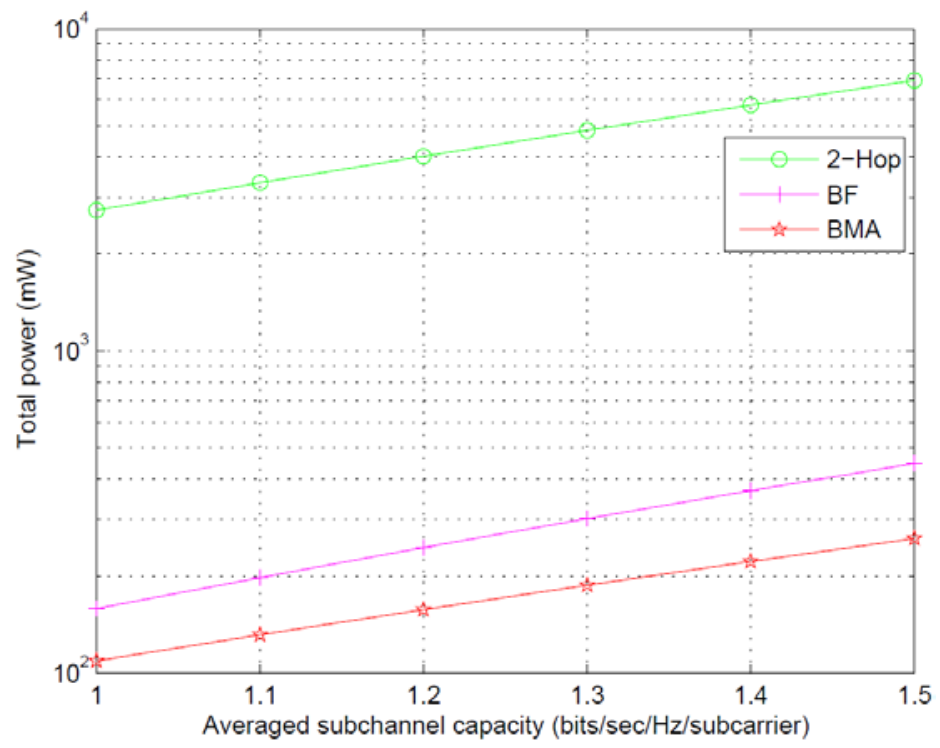

Fig. 9. Total power versus MSC.

performance than the two-hop system, while the AO algorithm enables the BMA system meet the requirement with the least power consumption. This is because with respect to the two-hop system, the BF scheme obtains spatial diversity from the direct link, while the general BMA system benefits from both the spatial diversity and the time diversity from the naturally timevarying relaying channel condition.

To show the detailed power allocation on each subcarrier for the two-hop, BF and BMA relay systems, powers on one hundred sub-channels (indexed from 701 to 800) are shown in Fig. 10-12, where the common minimal requirement of MSC is set to $3.5 \mathrm{bit} / \mathrm{s} / \mathrm{Hz} / \mathrm{subcarrier}$. The corresponding normalized channel gain on these subcarriers of the three systems can be found in Fig. 13.

In addition, given a fixed bandwidth, less total transmission power results in lower PSD. Note that it has been reported in [27], [28] and [29] that reduction in the PSD results in a lower 
electric field radiation from the signal being transmitted to a co-existing transmission system, as radiation is a function of the PSD. Thus, it can be hoped that this power saving property of the BMA scheme will relieve the EMI from PLC systems to the nearby radio systems to some extent.

\section{Conclusion}

By exploring both time diversity and spatial diversity from the relay-involved PLC channel, an iterative AO algorithm has been adopted to jointly optimize the source and relay power allocations for the general three-node/two-phase BMA relay system under indoor PLC environment. Specifically, we have examined the minimization of the total transmission power when there is a minimal channel MSC requirement for PLC applications. 2-Hop: $\operatorname{sum}\left(P_{S}\right)+\operatorname{sum}\left(P_{R}\right)=366.1239 \mathrm{~mW}$

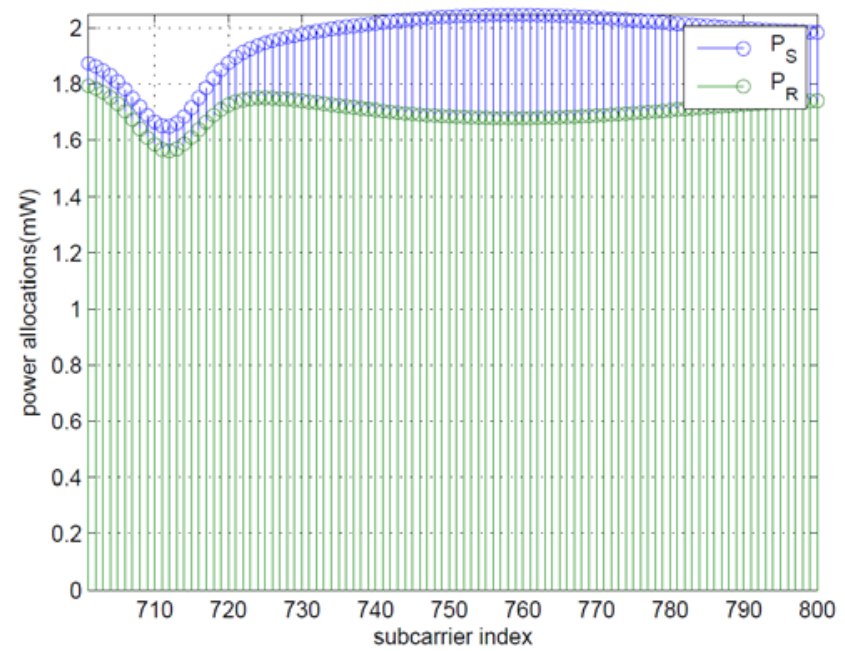

Fig. 10. Two-hop system.

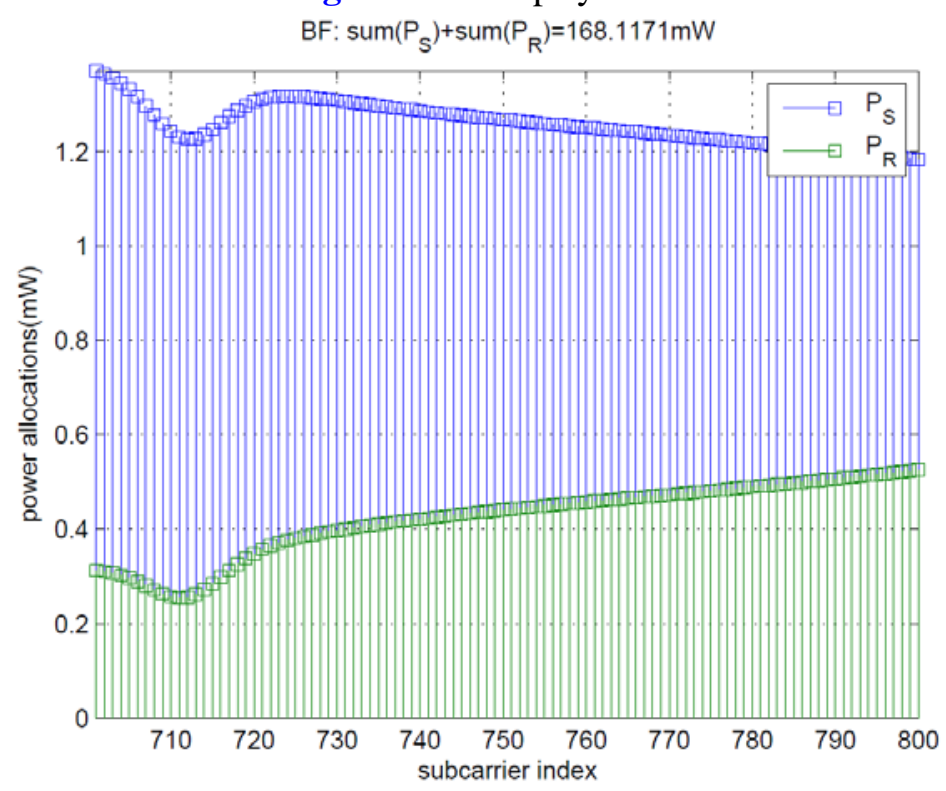

Fig. 11. BF system. 


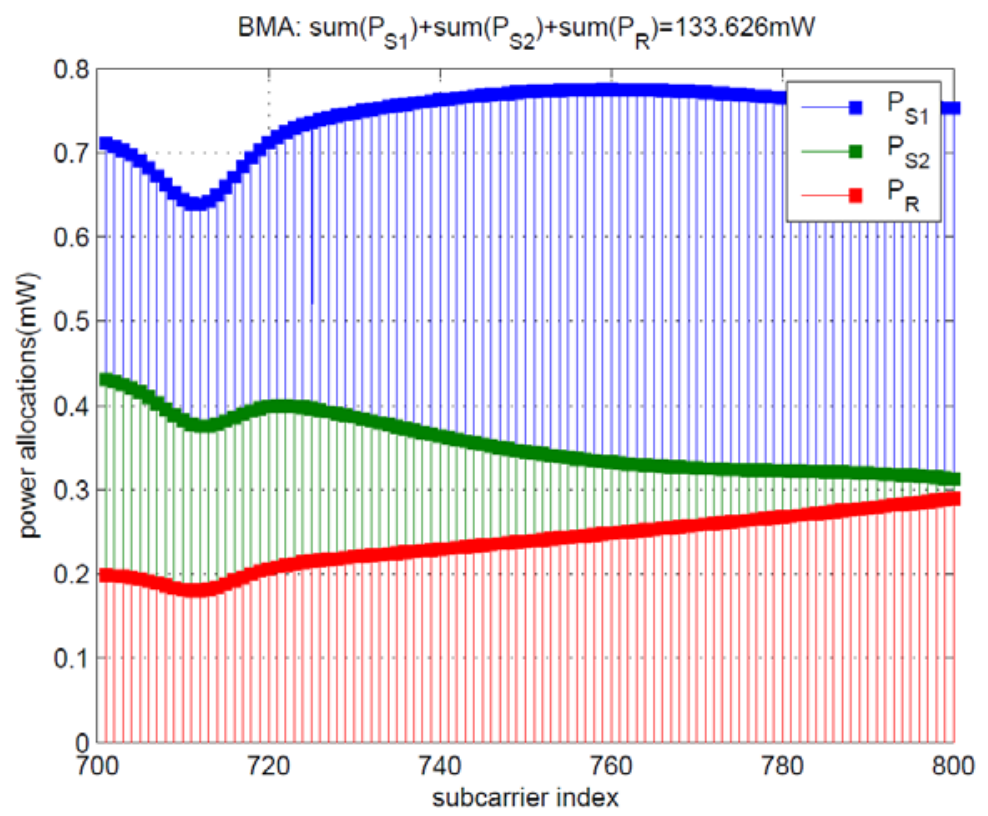

Fig. 12. BMA system.

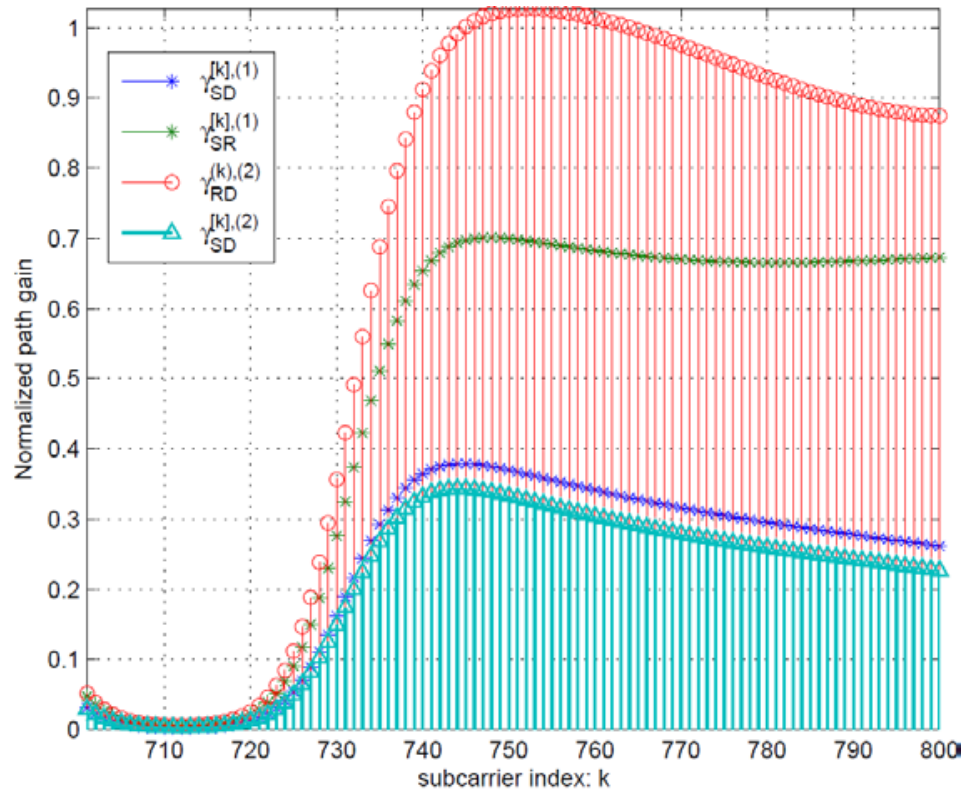

Fig. 13. Normalized path gain on subcarrier 701-800.

Simulation results have shown that compared to the two-hop and BF relay systems, the proposed algorithm can make the general BMA relay system attain the same QoS requirement with less total transmission power.

\section{Appendix A}

Lemma 1: Compound function - $\log _{2} \mathrm{f}(\mathrm{x})$ is convex on $\{\mathrm{x} \mid \mathrm{f}(\mathrm{x})>0\}$, if $\mathrm{f}(\mathrm{x})$ is concave. [25] Lemma 2: A non-negative weighted sum of convex (concave) functions is a convex (concave) 


\section{function. [25]}

Considering there is at least one solution to problem (13a)-(13c), so that the Lagrange multiplier $\lambda$ in (14a)-(Í14b) cannot take the value of 0 . Let us rewrite (13b) as $\sum_{k=1}^{K} \log _{2} f\left(x_{k}\right) \geq$ $2 \mathrm{q}$ where

And

$$
f\left(x_{k}\right)=A_{k}+\frac{D_{k}}{B_{k}+C_{k} x_{k}}+\frac{E_{k} \sqrt{x_{k}}}{\left(B_{k}+C_{k} x_{k}\right)^{2}}
$$

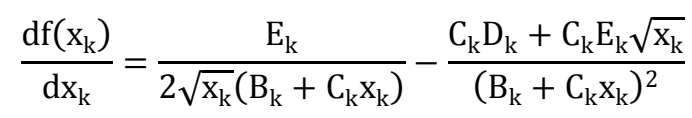

Note that $\frac{\mathrm{df}\left(\mathrm{x}_{\mathrm{k}}\right)}{\mathrm{dx_{ \textrm {k } }}}=0$ has the only solution on $\left\{\mathrm{x}_{\mathrm{k}} \mid \mathrm{x}_{\mathrm{k}} \geq 0, \mathrm{k}=1,2, \cdots \mathrm{K}\right\}$ as

$$
s_{k}=\frac{\sqrt{C_{k}^{2} D_{k}^{2}+C_{k} B_{k} E_{k}^{2}}-C_{k} D_{k}}{C_{k} E_{k}}
$$

and

$$
\begin{gathered}
f\left(s_{k}\right) \geq \lim _{x_{k} \rightarrow 0^{+}} f\left(x_{k}\right)=A_{k}+\frac{D_{k}}{B_{k}} \\
f\left(s_{k}\right) \geq \lim _{x_{k} \rightarrow+\infty} f\left(x_{k}\right)=A_{k}
\end{gathered}
$$

It can be seen from (20)-(22) that the peak value of $f\left(s_{k}\right)$ always occurs at $s_{k}$. This leads to the conclusion that the optimal $x_{k}$ satisfying (13b) occurs at $s_{k}$.

In addition, we note that when $0 \leq \mathrm{x}_{\mathrm{k}} \leq \frac{3 \mathrm{~B}_{\mathrm{k}}+2 \sqrt{3} \mathrm{~B}_{\mathrm{k}}}{3 \mathrm{C}_{\mathrm{k}}}$,

$$
\frac{\mathrm{d}^{2} \mathrm{x}_{\mathrm{k}}}{\mathrm{d} \mathrm{x}_{\mathrm{k}}^{2}} \leq 0
$$

Let us denote a subset of $\left\{\mathrm{x}_{\mathrm{k}} \mid \mathrm{x}_{\mathrm{k}} \geq 0, \mathrm{k}=1,2, \cdots \mathrm{K}\right\}$ as

$$
\chi=\left\{x_{k} \mid 0 \leq x_{k} \leq x_{k}^{*}, x_{k}^{*}=\frac{\left(1+\frac{2}{3} \sqrt{3}\right) B_{k}}{C_{k}}, k=1,2, \cdots K\right\} \text {. As } x_{k}^{*} \geq s_{k} \text {, subset } \chi \text { includes the }
$$
neighborhood of $s_{k}$, where $\mathrm{k}=1,2, \cdots \mathrm{K}$

Thus $\mathrm{f}\left(\mathrm{x}_{\mathrm{k}}\right)$ is positive and concave on $\chi$. By using Lemma 1 and 2, the LHS of (13b) is convex on $\chi$. Finally, as (13a) and (13c) are obviously convex on $\chi$, so that the problem (13a)-(13c) is convex on $\chi$.

Furthermore, from (20)-(22), we can see the LHS of (14b) is a piecewise monotone function of $\mathrm{x}_{\mathrm{k}}$. And (23) shows that the LHS of (16a) is monotonically decreasing on $\chi$.

\section{Appendix B}

It is easy to observe that $\delta$ cannot take the value of 0 . We rewrite the LHS of (15b) as

where

$$
2 \mathrm{q}-\sum_{\mathrm{k}=1}^{\mathrm{K}} \log _{2}\left(\mathrm{~F}+\mathrm{G}_{\mathrm{k}} \mathrm{y}_{\mathrm{k}}+\frac{\mathrm{H}_{\mathrm{k}}}{\mathrm{L}_{\mathrm{k}} \mathrm{y}_{\mathrm{k}}+\mathrm{M}_{\mathrm{k}}}+\mathrm{Y}_{\mathrm{k}}\right)
$$

$$
Y_{k}=\frac{R_{k} \sqrt{L_{k} y_{k}^{2}+y_{k}}}{L_{k} y_{k}+M_{k}}
$$

We can find that

$$
\begin{gathered}
\lim _{x_{k} \rightarrow 0^{+}} Y_{k}=0 \\
\lim _{x_{k} \rightarrow \infty} Y_{k}=\frac{R_{k}}{\sqrt{L_{k}}}
\end{gathered}
$$

In addition, when $y_{k} \geq 0$, we have 


$$
\begin{aligned}
& \frac{d Y_{k}}{d y_{k}} \geq 0 \\
& \frac{d^{2} Y_{k}}{d y_{k}^{2}} \leq 0
\end{aligned}
$$

Thus, $\mathrm{Y}_{\mathrm{k}}$ is increasing and concave on

$$
\left\{\mathrm{y}_{\mathrm{k}} \mid \mathrm{y}_{\mathrm{k}} \geq 0, \mathrm{k}=1,2, \cdots \mathrm{K}\right\}
$$

In addition, as $H_{k}<0, F_{k}, M_{k}>1$ and $G_{k}, L_{k}, R_{k}>0 \cdot \frac{H_{k}}{L_{k} y_{k}+M_{k}}$ is concave on $\left\{\mathrm{y}_{\mathrm{k}} \mid \mathrm{y}_{\mathrm{k}} \geq 0, \mathrm{k}=1,2, \cdots \mathrm{K}\right\}$. From Lemma 1 and 2 , the LHS of (15b) is convex on $\left\{\mathrm{y}_{\mathrm{k}} \mid \mathrm{y}_{\mathrm{k}} \geq 0, \mathrm{k}=1,2, \cdots \mathrm{K}\right\}$.

Furthermore, from (26) we can see the LHS of (16b) is a monotone function of $y_{k}$. And (27) shows that the LHS of (16a) is monotone to $y_{k}$.

\section{Appendix C}

It is easy to observe that $\delta$ cannot take the value of 0 . From their definitions, we know that $S_{k}, T_{k}, U_{k}>0$. In addition, it is obvious that $z_{k}$ and $\sqrt{z_{k}}$ is concave and non-negative on $\left\{z_{\mathrm{k}} \mid \mathrm{z}_{\mathrm{k}} \geq 0, \mathrm{k}=1,2, \cdots \mathrm{K}\right\}$.Using Lemma 1 and 2 leads us to the result that the LHS of (17b) is convex on $\left\{\mathrm{z}_{\mathrm{k}} \mid \mathrm{z}_{\mathrm{k}} \geq 0, \mathrm{k}=1,2, \cdots \mathrm{K}\right\}$.

Furthermore, it is easy to see that the LHS of (18a) is monotonically increasing with $z_{k}$ and the LHS of (18b) is a monotonously decreasing function of $z_{k}$, respectively.

\section{Appendix D}

Let us write $\mathrm{x}_{\mathrm{k}}, \mathrm{y}_{\mathrm{k}}$, and $\mathrm{z}_{\mathrm{k}}(\mathrm{k}=1,2, \ldots, \mathrm{K})$ in vector forms as $\mathbf{x}=\left[\mathrm{x}_{1}, \mathrm{x}_{2}, \cdots, \mathrm{x}_{\mathrm{K}}\right]^{\mathrm{T}}, \mathbf{y}=$ $\left[\mathrm{y}_{1}, \mathrm{y}_{2}, \cdots, \mathrm{y}_{\mathrm{K}}\right]^{\mathrm{T}}$ and $\mathbf{z}=\left[\mathrm{z}_{1}, \mathrm{z}_{2}, \cdots, \mathrm{z}_{\mathrm{K}}\right]^{\mathrm{T}}$,respectively, where $(\cdot)^{\mathrm{T}}$ denotes the vector transpose.

Since all the three sub-problems (13a)-(13c), (15a)-(15c) and (17a)-(17c) are convex/quasiconvex, the solution to each sub-problem is optimal. In other words, at a convergence point $\boldsymbol{\theta}^{\{n\}}=\left[\left(\mathbf{x}^{\{n\}}\right)^{T},\left(\mathbf{y}^{\{n\}}\right)^{T},\left(\mathbf{z}^{\{n\}}\right)^{T}\right]^{T}$, where the superscript $\{n\}$ fng denotes the variables at the $n t h$ iteration, we have

$$
\begin{aligned}
& \nabla_{x} P_{\Sigma}\left(\theta^{\{n\}}\right)^{T}\left(x-x^{\{n\}}\right) \geq 0 \\
& \nabla_{y} P_{\Sigma}\left(\theta^{\{n\}}\right)^{T}\left(y-y^{\{n\}}\right) \geq 0 \\
& \nabla_{z} P_{\Sigma}\left(\theta^{\{n\}}\right)^{T}\left(z-z^{\{n\}}\right) \geq 0
\end{aligned}
$$

Here $\nabla_{\alpha} \mathrm{P}_{\Sigma}\left(\theta^{\{\mathrm{n}\}}\right)$ denotes the gradient of the objective function(12a) along the direction of $\alpha \in\{\mathrm{x}, \mathrm{y}, \mathrm{z}\}$ at $\theta^{\{\mathrm{n}\}}$.

By summing up (28a)-(28c), we obtain

where

$$
\nabla P_{\Sigma}\left(\theta^{\{n\}}\right)^{T}\left(\theta-\theta^{\{n\}}\right) \geq 0
$$

This indicates that $\theta^{\{n\}}$ is a stationary point of (12a).

$$
\nabla \mathrm{P}_{\Sigma}\left(\vartheta^{\{n\}}\right)=\left[\nabla_{\mathrm{x}} \mathrm{P}_{\Sigma}\left(\theta^{\{\mathrm{n}\}}\right)^{\mathrm{T}}, \nabla_{\mathrm{y}} \mathrm{P}_{\Sigma}\left\{\theta^{\{n\}}\right\}^{\mathrm{T}}, \nabla_{\mathrm{z}} \mathrm{P}_{\Sigma}\left(\theta^{\{\mathrm{n}\}}\right)^{\mathrm{T}}\right]^{\mathrm{T}}
$$




\section{References}

[1] S. Mudriievskyi, "Power line communications: State of the art in research, development and application," AEU-International Journal of Electronics and Communications, vol.68, no.7, pp.575-577, 2014. Article (CrossRef Link)

[2] H.C. Ferreira, L. Lampe, J. Newbury, and T.G. Swart, "Power Line Communications: Theory and Applications for Narrowband and Broadband Communications over Power Lines,” Wiley, 2010. Article (CrossRef Link)

[3] S. Güzelgöz , H. Arslan, A. Islam and A. Domijan, "A review of wireless and PLC propagation channel characteristics for smart grid environments," Journal of Electrical and Computer Engineering, vol. 2011, p. 5, 2011. Article (CrossRef Link)

[4] H. Sun, A. Nallanathan, N. Zhao and C. Wang, "Green Data Transmission in Power Line Communications,” in Proc. of IEEE GLOBECOM 2012, Anaheim CA, Dec, 2012. Article (CrossRef Link)

[5] N. Zhao, F. R. Yu, H. Sun, H. Yin, A. Nallanathan and G. Wang, "Interference Alignment with Delayed Channel State Information and Dynamic AR-Model Channel Prediction in Wireless Networks," Wireless Networks, 21(4): 1227-1242, 2015. Article (CrossRef Link)

[6] H. A. Latchman, S. Katar, L. W. Yonge III, and S. Gavette, "Homeplug AV and IEEE 1901: A Handbook for PLC Designers and Users,” Wiley, 2013. Article (CrossRef Link)

[7] H. Elshaafi, M. Vinyals, M. Dibley, I. Grimaldi and M. Sisinni, "Combination of Standards to Support Flexibility Management in the Smart Grid," in Proc. of Challenges and Opportunities. In Smart Grid Inspired Future Technologies: First International Conference, SmartGIFT 2016, Liverpool, UK, May 19-20, pp. 143-151, Revised Selected Papers, Springer International Publishing, 2017. Article (CrossRef Link)

[8] L. T. Berger, A. Schwager, P. Pagani, and D. M. Schneider, "MIMO Power Line Communications: Narrow and Broadband Standards, EMC, and Advanced Processing," France, CRC Press, 2014.

[9] H.S. Nguyen, D.T. Do, and M. Voznak, "Two-way relaying networks in green communications for 5g: Optimal throughput and tradeoff between relay distance on power splitting-based and time switching based relaying swipt," AEU-International Journal of Electronics and Communications, vol.70, no.12, pp.1637-1644, 2016. Article (CrossRef Link)

[10] B. Praho, M. Tlich, P. Pagani, A. Zeddam, and F. Nouvel, "Cognitive detection method of radio frequencies on power line networks," in Proc. of Power Line Communications and Its Applications (ISPLC), 2010 IEEE International Symposium on, pp.225-230, IEEE, 2010. Article (CrossRef Link)

[11] G. Bumiller, "Single frequency network technology for medium access and network management," in Proc. of 6th International Symposium on Power-Line Communications and its applications, 2002.

[12] L. Lampe, R. Schober, and S. Yiu, "Distributed space-time coding for multi hop transmission in power line communication networks," Selected Areas in Communications, IEEE Journal on, vol.24, no.7, pp.1389-1400, 2006. Article (CrossRef Link)

[13] L. Lampe and A.H. Vinck, "On cooperative coding for narrow band PLC networks," AEU-International Journal of Electronics and Communications, vol.65, no.8, pp.681-687, 2011. Article (CrossRef Link)

[14] X.Wu, "Reliable indoor power line communication systems: via application of advanced relaying processing," Ph.D. dissertation, Dept. Electrial and Computer Eng., Curtin University, Perth, WA, Australia, 2015.

[15] S. D'Alessandro, A.M. Tonello, and F. Versolatto, "Power savings with opportunistic decode and forward over in-home PLC networks," in Proc. of Power Line Communications and Its Applications (ISPLC), 2011 IEEE International Symposium on, pp.176-181, IEEE, 2011. Article (CrossRef Link)

[16] W. Zhang, U. Mitra, and M. Chiang, "Optimization of amplify-and forward multicarrier two-hop transmission,” Communications, IEEE Transactions on, vol.59, no.5, pp.1434-1445, 2011. Article (CrossRef Link) 
[17] Y. Li,W.Wang, J.Kong,W. Hong, X. Zhang, and M. Peng, "Power allocation and subcarrier pairing in OFDM-based relaying networks," in Proc. of Communications, 2008. ICC'08. IEEE International Conference on, pp.2602-2606, IEEE, 2008. Article (CrossRef Link)

[18] I. Hammerstrom and A. Wittneben, "On the optimal power allocation for non regenerative OFDM relay links,” in Proc. of Communications, 2006. ICC'06. IEEE International Conference on, pp.4463-4468, IEEE, 2006. Article (CrossRef Link)

[19] Y. Ma, A. Liu, and Y. Hua, "A dual-phase power allocation scheme for multicarrier relay system with direct link,” Signal Processing, IEEE Transactions on, vol.62, no.1, pp.5-16, 2014. Article (CrossRef Link)

[20] N. Papandreou and T. Antonakopoulos, "Bit and power allocation in constrained multicarrier systems: the single-user case,” EURASIP Journal on Advances in Signal Processing, vol.2008, p.11, 2008. Article (CrossRef Link)

[21] Y. Rong, X. Tang, and Y. Hua, "A unified framework for optimizing linear nonregenerative multicarrier mimo relay communication systems," Signal Processing, IEEE Transactions on, vol.57, no.12, pp.4837-4851, 2009. Article (CrossRef Link)

[22] F. Canete, J. Cortes, L. Diez, and J. Entrambasaguas, "A channel model proposal for indoor power line communications,” Communications Magazine, IEEE, vol.49, no.12, pp.166-174, December 2011. Article (CrossRef Link)

[23] M. Zimmermann and K. Dostert, "Analysis and modeling of impulsive noise in broad-band powerline communications,” Electromagnetic Compatibility, IEEE Transactions on, vol.44, no.1, pp.249-258, Feb 2002. Article (CrossRef Link)

[24] Y.S. Sung, J.H. Lee, Y.H. Kim, and S.C. Kim, “Optimal subcarrier pairing scheme for maximal ratio combining in ofdm power line communications,” AEU-International Journal of Electronics and Communications, vol.68, no.9, pp.893-898, 2014. Article (CrossRef Link)

[25] S. Boyd and L. Vandenberghe, “Convex Optimization,” Cambridge University Press, 2004. Article (CrossRef Link)

[26] "HomeplugAV white paper.” http://www.homeplug.org/products/whitepapers,2007.

[27] T. S. Pang, L. S. Ping, and Y. S. Kye, "Feasibility Study of a New Injection Method for EMI Reduction in Indoor Broadband PLC Networks," IEEE Transactions on Power Delivery 25.4, 2392-2398, 2010. Article (CrossRef Link)

[28] K. Y. See, P. L. So, and A. Kamarul, "Feasibility study of adding a common-mode choke in PLC modem for EMI suppression," IEEE Transactions on Power Delivery 22.4, 2136-2141, 2007. Article (CrossRef Link)

[29] R. L. Itagi, K. P. Vittal, and U. Sripati, "A low SNR approach to substation communication using powerline for EMI reduction," in Proc. of Electromagnetic Compatibility (APEMC), 2012 Asia-Pacific Symposium on. IEEE, 2012. Article (CrossRef Link) 

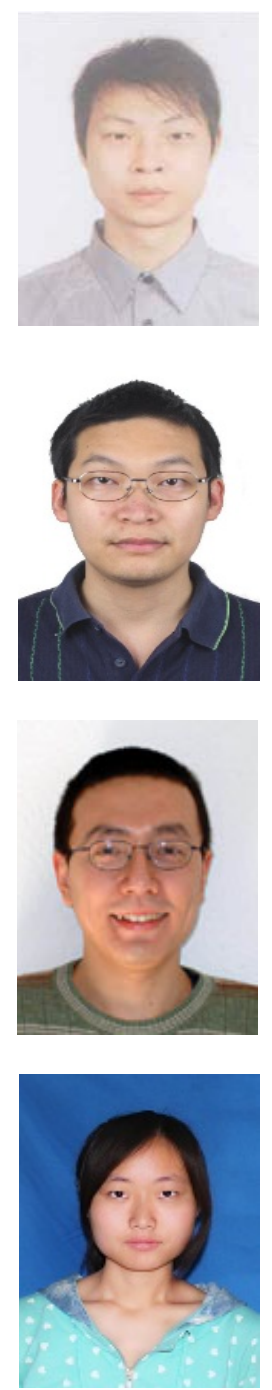

Xiaolin Wu received the M.Sc. degree from Chongqing University, Chongqing, China, and the Ph.D. degree from Curtin University, Perth, Australia, both in electrical and computer engineering, in 2010 and 2015, respectively. Since December 2016, he has been with the College of Communication Engineering, Chongqing University, where he is now a Postdoctoral Researcher. His research interests include power line communications and networks, information security, statistical and array signal processing.

Bin Zhu received the M.S. degree and the Ph.D. degree in 2007 and 2010 respectively, both in Communication and Information System, from Chongqing University, China. Since Sep. 2011, Dr. Zhu has been working as an associate professor at College of Communication Engineering, Chongqing University, Chongqing, China. From Apr. 2014to Apr. 2015, he was a visiting scholar at the Department of Computer Science and Engineering in the State University of New York at Buffalo, New York, U.S. His research interests include power line communication, wireless networking and privacy, security and trust in body area networks.

Yue Rong was born in 1976, Jiangsu, China. He received the B.E. degrees from Shanghai Jiao Tong University, Shanghai, China, the M.Sc. degree from the University of Duisburg-Essen, Duisburg, Germany, and the Ph.D. degree (summa cum laude) from Darmstadt University of Technology, Darmstadt, Germany, all in electrical engineering, in 1999, 2002, and 2005, respectively. His research interests include signal processing for communications, wireless communications, wireless networks, and statistical and array signal processing.

Yang Wang is pursuing her Master degree in Communication and Information System in Chongqing University, China. Her research interests include wireless networking and clustering in Wireless Sensor Networks. 